\title{
The Need to Consider Vestibular Function in Cochlear Implantation
}

\author{
Yoon Chan Rah (i) \\ Department of Otorhinolaryngology-Head and Neck Surgery, Korea University Ansan Hospital, Korea University College of Medicine,
} Ansan, Korea

Cochlear implantation (CI) is currently the only treatment method capable of restoring hearing in patients with severe to profound hearing loss. Although the safety and effectiveness of CI are widely accepted, there is a concern that insertion of electrodes into the perilymphatic space of the inner ear could affect vestibular sensory receptors. In particular, the recent increase in bilateral implantation could be associated with a higher risk of refractory vestibular dysfunction. However, during CI planning, such as selection of the side or method of implantation, vestibular function is still not considered important since achieving the best audiologic performance is crucial for implantees. However, the incidence of vestibular impairment after CI has been reported to be as high as $75 \%$, indicating that its importance should be recognized [1-3].

Among patients who experience dizziness after CI, most (up to $63 \%$ ) have been found to experience transient dizziness early after CI, which improves in several days, while persistent or recurrent dizziness has been reported in up to $32 \%$ of implantees $[2,4]$. The speculated reasons for early transient dizziness are mostly benign paroxysmal positional vertigo or reversible transient vestibular paresis, whereas significant vestibular dysfunction or associated auditory symptoms were more frequently observed in persistent or recurrent cases $[2,4]$. The suspected mechanisms are as follows: a direct injury or perilymphatic fistula [4-6], associated labyrinthitis [1], chronic foreign body reaction and fibrosis [2,5], and formation of endolymphatic hydrops [1,5]. Saccular injury was most frequently observed in vestibular organs, followed by injuries of the utricle and semicircular canals [5,7]. In this regard, previous studies reported that CI-associated vestibular impairment can be effectively assessed using vestibular myogenic potential or bithermal caloric tests $[4,8,9]$.

The reported prevalence of underlying vestibular dysfunction in candidates for $\mathrm{CI}$ is as high as $71 \%$; therefore, a preoperative assessment of vestibular function and careful consideration dur- ing surgical planning are required [4,10]. In particular, meticulous attention is required in elderly patients or patients with preoperatively confirmed vestibular dysfunction, as these patients may have a diminished functional rehabilitative reservoir [6]. In addition, bilateral CI was reported to be associated with a higher risk of dizziness and vestibular impairment [11]. If possible, sequential bilateral implantation with a careful assessment for changes in vestibular function after the first surgery could be considered. The recently emphasized concept of "soft surgery" has shown positive results in terms of reducing CI-induced vestibular impairment through the selection of a round window approach rather than a cochleostomy [3,4], the insertion of precurved or soft electrodes [12], and steroid administration [6]. However, active research on this topic is ongoing, and a definitive conclusion can be drawn only with adequate data $[3,4,8,13]$.

Evidence suggests that vestibular function can be affected by $\mathrm{CI}$, and a considerable number of candidates for $\mathrm{CI}$ have underlying vestibular dysfunction. Therefore, vestibular function must be carefully assessed and considered during the planning and clinical procedures for $\mathrm{CI}$, especially in patients undergoing bilateral CI or those with an elevated risk of vestibular dysfunction.

\section{CONFLICT OF INTEREST}

No potential conflict of interest relevant to this article was reported.

\section{ORCID}

Yoon Chan Rah https://orcid.org/0000-0003-1559-5396

Copyright (C) 2021 by Korean Society of Otorhinolaryngology-Head and Neck Surgery.

This is an open-access article distributed under the terms of the Creative Commons Attribution Non-Commercial License (https://creativecommons.org/licenses/by-nc/4.0)

which permits unrestricted non-commercial use, distribution, and reproduction in any medium, provided the original work is properly cited. 


\section{REFERENCES}

1. Fina M, Skinner M, Goebel JA, Piccirillo JF, Neely JG, Black O.Vestibular dysfunction after cochlear implantation. Otol Neurotol. 2003 Mar;24(2):234-42.

2. Kubo T, Yamamoto K, Iwaki T, Doi K, Tamura M. Different forms of dizziness occurring after cochlear implant. Eur Arch Otorhinolaryngol. 2001 Jan;258(1):9-12.

3. Todt I, Basta D, Ernst A. Does the surgical approach in cochlear implantation influence the occurrence of postoperative vertigo? Otolaryngol Head Neck Surg. 2008 Jan;138(1):8-12.

4. Rah YC, Park JH, Park JH, Choi BY, Koo JW. Dizziness and vestibular function before and after cochlear implantation. Eur Arch Otorhinolaryngol. 2016 Nov;273(11):3615-21.

5. Handzel O, Burgess BJ, Nadol JB Jr. Histopathology of the peripheral vestibular system after cochlear implantation in the human. Otol Neurotol. 2006 Jan;27(1):57-64.

6. Enticott JC,Tari S, Koh SM, Dowell RC, O'Leary SJ. Cochlear implant and vestibular function. Otol Neurotol. 2006 Sep;27(6):824-30.

7. Tien HC, Linthicum FH Jr. Histopathologic changes in the vestibule after cochlear implantation. Otolaryngol Head Neck Surg. 2002 Oct; 127(4):260-4.

8. Jang JH, Kim H, Choo OS, Park HY, Choung YH. Changes in vestibular symptoms and function after cochlear implantation: relevant factors and correlations with residual hearing. Clin Exp Otorhinolaryngol. 2021 Feb;14(1):69-75.

9. Basta D, Todt I, Goepel F, Ernst A. Loss of saccular function after cochlear implantation: the diagnostic impact of intracochlear electrically elicited vestibular evoked myogenic potentials. Audiol Neurootol. 2008;13(3):187-92.

10. Krause E, Louza JP, Hempel JM,Wechtenbruch J, RaderT, Gurkov R. Prevalence and characteristics of preoperative balance disorders in cochlear implant candidates. Ann Otol Rhinol Laryngol. 2008 Oct; 117(10):764-8.

11. Wagner JH, Basta D, Wagner F, Seidl RO, Ernst A, Todt I. Vestibular and taste disorders after bilateral cochlear implantation. Eur Arch Otorhinolaryngol. 2010 Dec;267(12):1849-54.

12. Frodlund J, Harder H, Maki-Torkko E, Ledin T. Vestibular function after cochlear implantation: a comparison of three types of electrodes. Otol Neurotol. 2016 Dec;37(10):1535-40.

13. Louza J, Mertes L, Braun T, Gurkov R, Krause E. Influence of insertion depth in cochlear implantation on vertigo symptoms and vestibular function. Am J Otolaryngol. 2015 Mar-Apr;36(2):254-8. 